\author{
TARAS POLOVYI \\ Lviv Polytechnic National University \\ ORCID: https://orcid.org/0000-0002-7908-6606
}

\title{
Формирование отрицательного образа Запада в белорусских медиа после политического кризиса 2020 года. Кейс телеканала ОНТ'
}

\section{Formation of a negative image of the West in the Belarusian media after the political crisis of 2020. The case of ONT TV channel}

\section{Abstract}

This article presents the results of the content monitoring of news programs of the Belarusian state TV channel ONT. Revealed, that from a certain period on the Belarusian television pro-Russian narratives used to create a negative image of the West in the viewer have been promoted. Shown that in the stories of this media the West is portrayed in the context of its destructive impact on the Republic of Belarus. Noted, that special attention is paid to the protests of 2020 in Belarus. According to the rhetoric of the ONT TV channel, the mentioned actions, being inspired by Western countries, are an element of the West's war against Russia. The author attempted to analyze the attitude of the Belarusian society to the Western world. Emphasized, that the fixed sociologists' attitude of Belarusians to the West indicates that the bipolar picture of the world offered by this TV channel, at this stage, is generally not shared by the Belarusian society.

1 Статья подготовлена в рамках участия в Visegrad Scholarship Program, на базе Кафедры Международных Отношений и Современной Истории, Факультета Истории и Международных Отношений Белостоцкого университета. 
Keywords: the portrayal of the West, pro-Russian narratives, anti-Western rhetoric, Belarusian television, ONT TV channel

\section{Формирование отрицательного образа Запада в белорусских медиа после политического кризиса 2020 года. Кейс телеканала OHT}

\section{Аннотация}

В данной статье представлены результаты мониторинга контента новостных программ белорусского государственного телеканала ОНТ. Выявлено, что с определенного периода на белорусском телевидении продвигаются пророссийские нарративы, применяемые для создания у телезрителя отрицательного образа Запада. Продемонстрировано, что в сюжетах данного СМИ Запад изображается в контексте его деструктивного воздействия на Республику Беларусь. Утверждается, что белорусскому зрителю навязывается необходимость выбора между воинственным Западом и дружественной Россией. Отмечено, что особое внимание уделено акциям протеста 2020 года в Беларуси. Согласно риторике телеканала ОНТ, упомянутые акции, будучи инспирированными западными странами, являются элементом войны Запада против России. Автором осуществлена попытка анализа отношения белорусского общества к западному миру. Подчеркнуто, что зафиксированное социологами отношение белорусов к Западу свидетельствует о том, что биполярная картина мира, предлагаемая данным телеканалом, на данном этапе в целом не разделяется белорусским обществом. Обращено внимание, что наличие в белорусском информационном пространстве широкой сети пророссийских интернет-медиа и соответственная риторика, используемая на местном телевидении, создают благоприятные условия для массового воздействия на белорусскую аудиторию.

Ключевые слова: образ Запада, пророссийские нарративы, антизападная риторика, белорусское телевидение, телеканал ОНТ

\section{Введение}

Сеополитическое расположение Республики Беларусь как самостоя ятельного независимого государства между Востоком и Западом с начала 1990-х годов побудило политическое руководство молодой страны к необходимости цивилизационного самоопределения. К традиционной дихотомии Восток-Запад прилагалась концепция 
нейтралитета, согласно которой белорусскому государству отводилась роль своеобразного “моста” между двумя цивилизациями. Учитывая практическое отсутствие предметного интереса западных элит по интеграции Беларуси в свое политическое, экономическое, культурное пространство и принимая во внимание отсутствие осмысленного запроса внутри тогдашнего белорусского общества, в итоге доминирующим стало российское направление с элементами нейтралитета во внешней политике. В то время западному вектору на протяжении длительного времени отводилась второстепенная роль.

Таким образом, за почти 30 лет независимости ориентация на Россию стала зачастую безальтернативной, что со временем переросло в значительную зависимость Беларуси от РФ в различных сферах. Одним из ключевых в этом плане является информационное пространство - телевидение и интернет-медиа, которые сформировались и продолжают функционировать под значительным российским влиянием. При этом информационное проникновение со стороны запада всячески ограничивалось белорусскими властями. Более того, многолетний период правления Александра Лукашенко отмечается периодическим обострением антизападной риторики ${ }^{2}$ (В тумане гибридной войны, 2020), как со стороны официальных властей, так и существующих в Беларуси СМИ, которые формируют общественное мнение относительно Запада.

Применяя в данной статье категорию “Запад” будем иметь в виду, прежде всего, страны участники ЕС и США, поскольку именно к этим субъектам международных отношений зачастую апеллирует российская пропаганда в Беларуси, осуществляя тем самым влияние на формирование совокупного образа Запада в белорусском обществе.

2 Антизападничество Лукашенко, равно как, впрочем, и его пророссийскость, являются одновременно и имманентными, и конъюнктурными при откровенном доминировании последнего фактора. Федоров, 2020. 


\section{Методология}

В данной статье осуществлено попытку анализа новостного контента белорусского государственного телеканала ОНТ. Исследование проводилось с применением метода мониторинга с элементами качественного контент-анализа, с целью определения общего отношения к Западу на выбранном телеканале. Применение указанных методов осуществлялось к отобранным материалам из новостных эфиров и других передач на политическую тематику, в которых встречались упоминания так называемого “коллективного Запада” либо отдельных западных стран. Проанализированы материалы эфиров телеканала ОНТ в период августа 2020 года - января 2021 года. Выбор хронологических рамок обусловлен развертыванием политического кризиса в Беларуси и началом работы российских специалистов на белорусском телевидении, что было подтверждено Александром Лукашенко в августе 2020 года (Лукашенко подтвердил работу российских пропагандистов на ТВ в Беларуси, 2020). Пятимесячный период мониторинга позволяет делать определенные выводы касательно используемой в отдельных сюжетах риторики, а также основных нарративов, употребляемых на телеканале ОНТ в отношении Запада.

\section{Медиасфера Беларуси. Кейс телеканала ОНТ}

Важным фактором при рассмотрении данной проблемы является популярность российских медиа в Беларуси ${ }^{3}$ (Александров, 2020) и присутствие в информационном пространстве координированной сети пророссийски ориентированных пропагандистских региональных СМИ (Елисеев, 2019), которым свойственно использование антизападной риторики и деятельность направлена на последовательную дискредитацию Запада. Вместе с этим, исходя из результатов мониторинга, проведенного Белорусской ассоциацией журналистов с целью

3 Согласно данных мониторинга проведенного Белорусской ассоциацией журналистов, в 2020 г. государственные телеканалы демонстрировали в прайм-тайм более $60 \%$ продукции российского производства. В: Мониторинг пророссийской пропаганды в медиа Беларуси 2019. 
выявления присутствия российской тематики и пророссийской пропаганды в СМИ, основным источником пророссийской пропаганды в Беларуси остается телевидение (Мониторинг пророссийской пропаганды в медиа Беларуси, 2019).

Таким образом, отрицательный образ Запада в Беларуси формируется в том числе и через телевидение, которое, оставаясь важным источником информации для жителей Беларуси, является весомым инструментом продвижения соответствующих нарративов в белорусском медиапространстве. Согласно результатам исследования, проведенного Информационно-аналитическим центром при Администрации президента Беларуси в 2018 году, для 72\% граждан основным источником информирования о ситуации в стране и за рубежом являлось телевидение (Республика Беларусь в зеркале социологии, 2018, с. 133). В частности, согласно результатам опроса, приведенного в рамках данного исследования, наиболее популярный среди белорусских зрителей национальный канал ОНТ. Кроме количественных показателей, данный канал отличается довольно высокими (81\% от числа опрошенных) качественными характеристиками и является одним из доминирующих в плане доверия зрителей относительно транслируемого контента ( $\mathrm{Pe}$ спублика Беларусь в зеркале социологии, 2018, с. 137-138).

Телеканал ОНТ, или Общенациональное телевидение, основан в 2002 году. Слоганом канала является фраза: “То, что нас объединяет”. Заявленная тематика канала - это развлекательно-познавательные программы собственного производства, как и заимствованные рейтинговые программы российского “Первого канала”. Учитывая эту специфику, ОНТ частично можно отнести к категории так называемых “гибридных телеканалов”, которые, будучи зарегистрированными в Беларуси, значительную часть своего контента заимствуют в России. После того как на государственные телеканалы в том числе и на ОНТ были трудоустроены специалисты из России вместо бастующих и уволившихся сотрудников. Таким образом, телевидение в Беларуси, которое раньше полностью контролировалось белорусскими властями, попало под российский контроль (Гибридная интервениия, 2020). На таком фоне наблюдется активизация антизападной риторики в новостном контенте данного телеканала. Обращает на себя внимание 
и привлечение в качестве экспертов и политологов, кроме белорусских, также российских и украинских граждан, что внешне создавало картину о многообразии мнений и оценок, озвучиваемых на данном телеканале. Однако, как показал мониторинг, по сути, комментаторы транслируют похожие, а временами и идентичные нарративы в отношении Запада и Беларуси.

Указанные обстоятельства, а также усиление российского информационного влияния после политического кризиса 2020 года в Беларуси дало основания экспертам утверждать, что практически вся медиаповестка белорусских государственных СМИ синхронизирована с (про) кремлевскими (Елисеев, 2020). Кроме того, по оценкам медиа-аналитиков, влияние российских СМИ в Беларуси настолько значительно, поскольку белорусская медиа система на сегодняшний день фактически разрушена (Морозов, 2020).

Учитывая значение телевидения в процессе информирования белорусского общества, важно раскрыть отношение граждан к Западу, рассмотреть основные нарративы, используемые относительно ЕС и США. Задача также заключается в том, чтобы проанализировать позиционирование образа Запада на одном из ведущих государственных телеканалов Беларуси, каким является ОНТ..

\section{Восприятие Запада белорусским обществом}

Исходя из вышеупомянутого, стоит отметить, что белорусское общество причисляют к наиболее антизападным среди всех стран Восточного партнерства. Анализируя причины, которые обусловили такую конъюнктуру, белорусский исследователь, директор Belarus Institute for Strategic Studies (BISS) Пётр Рудковский пришел к выводу, что весомым основанием для российской пропаганды и роста антизападных настроений является слабая национальная идентичность белорусов (Рудкоўскі, 2019).

Превалирование несколько иных тенденций можно наблюдать, в результатах национального опроса, проведенного 21 августа 2020 года в Беларуси по заказу американской газеты “The Washington Post”. Отвечая на вопросы о собственных внешнеполитических приоритетах, 
$50,4 \%$ респондентов в возрасте от 18 до 40 лет утверждали, что хотят двигаться в направлении Запада, а 23,3\% - в сторону России. А в группе старше 60 лет только 14,7\% - стремятся в сторону Запада, а 62\% хотят двигаться желали двигаться геополитическим путем России. Также практически половина опрошенных белорусов высказалась за хорошие отношения с НАТО, при этом явное большинство не желает присоединяться к альянсу. Более трех четвертей согласились с тем, что лучше оставаться нейтральным государством. И только трое из 10 респондентов видят в западной культуре угрозу (Toal, O’Loughlin, Bakke, 2020). Принимая во внимание приведенные данные, можно отметить, что белорусам на данном этапе присуща открытость к Западу, при одновременном желании сохранения тесных связей с Россией.

В таком же контексте уместно привести цитату из исследования, проведенного варшавским Центром восточных студий (OSW), о том утверждается, что “белорусы более или менее осознанно воспринимают себя как нацию, которая находится между Востоком и Западом, на стыке разных цивилизаций, что обуславливает своеобразное сочетание противоположностей” (Białorusini o Polsce, Rosji i sobie, 2021). Кроме того, весьма сдержанное и осторожное отношение белорусов к западному миру объясняется определенной инерцией, присущей, русскому, белорусскому и украинскому обществам еще с периода “холодной войны”. Советская пропаганда на протяжении длительного времени систематически маргинализировала и демонизировала Запад с целью закрепления в обществе образа врага, что не могло остаться без следа в коллективном подсознании. Такие тенденции в определенный способ иллюстрируют и приведенные выше результаты опроса в различных возрастных группах.

\section{Дискредитация Запада и пророссийские нарративы на телеканале ОНТ}

Учитывая существующее противостояние России с Западом, а также российское информационное присутствие в белорусском медиапространстве, антизападная риторика стала одним из элементов пропагандистской деятельности в Беларуси. Результатом чего стало усиление 
критики Запада посредством использования определенных нарративов, которые, в большинстве случаев, имеют негативный контекст. Запад изображается как агрессивное объединение государств, пытающихся дестабилизировать ситуацию в Беларуси и захватить сферу влияния России, которой является постсоветское пространство. Таким образом, "угрожая Беларуси, Запад на самом деле ведет войну с Россией, рассматривая Беларусь как “полигон” для организации целенаправленной антироссийской деятельности” (Санкиии и давление на Россию, 2020). Данный тезис неоднократно озвучивался и Александром Лукашенко (Лукашенко российским СМИ, 2020), после чего был подхвачен и активно отрабатывался, в частности, телеканалом ОНТ (Лукашенко: Я не единожды говорил, что Беларусь им нужна как трамплин для атаки на Россию, 2021). Например, в одном из сюжетов говорится о военной угрозе Беларуси со стороны Запада, который “пытаясь использовать Беларусь против России, в перспективе, может перенаправить войска и вооружение, находящееся в Польше на территорию Беларуси" (Чем грозит выход ситуаиии из-под контроля?, 2020). Продвигается мысль, что “европейские страны, воспринимая Беларусь как колонию, стремятся путем информационной войны сначала завоевать чужие умы, а после чего и перекроить существующие границы” (Протесть-2020, 2020).

Отмечая ухудшение отношений Запада и России, утверждается, что “2021 год Запад выбрал для обострения войны с Россией и используя санкции пытается разрушить страну изнутри” (Санкции и давление на Россию, 2020). Таким образом, российская новостная повестка с использованием нарративов, применяемых на российских телеканалах, переносится в белорусское информационное пространство, а белорусские государственные интересы фактически отождествляются с российскими. В этом контексте продвигается нарратив об общей угрозе со стороны Запада. “Создавая внешние проблемы для отвлечения внимания от своих внутренних противоречий, Запад запустил управляемый процесс региональной дестабилизации от Балтийского до Черного и Каспийского моря. И именно “белорусский выступ” является последним бастионом в создаваемой мероприятием евразийской дуге нестабильности, в которую входят Нагорный Карабах, Приднестровье, Украина, а теперь и Беларусь” (Санкции и давление на Россию, 2020). 
Апеллируя к образам времен Второй мировой войны, Беларусь метафорически позиционируется как Брестская крепость на пути в Россию и Китай (Флаги и символь коллаборационистов..., 2020). Следовательно, “Россия и Беларусь совместно борются с Западом за свое будущее” (Зюганов о ситуации в Беларуси..., 2020). Таким образом, белорусскому обществу навязывается мнение, что эскалация конфликтов и дестабилизация ситуации на постсоветском пространстве является следствием исключительно западных провокаций, направленных против России. Соответственно, в противовес агрессивному Западу ставится Россия, которая призвана защитить Беларусь.

Возрастание количества упоминаний о деструктивном влиянии Запада наблюдается, в основном, в материалах, освещающих тему белорусских акций протеста 2020 года. В частности, протесты, происходившие на фоне белорусского политического кризиса, являются “попыткой Запада осуществить в республике так называемую “цветную революцию”, следующим витком которой станет распространение на территорию России” (Зюганов о ситуации в Беларуси..., 2020). Следовательно, протесты в Беларуси вызваны не внутриполитическими противоречиями, а трактуются, прежде всего, как внешнеполитическое давление и вмешательство во внутренние дела Беларуси (Эксперты: Беларусь столкнулась..., 2020).

В репортаже канала ОНТ под названием "Кто и зачем призывает белорусов подорвать собственную экономику” среди прочего утверждается, что “зарубежные координаторы протестов в Беларуси с помощью телеграмм каналов призывают белорусов подорвать собственную экономику. Пытаясь навязать сценарий чем хуже тем лучше" (Кто и зачем призывает белорусов..., 2020). Соответственно, “будучи плацдармом для борьбы за человеческие ресурсы и территории” (Протесты-2020, 2020), “белорусское государство и белорусское население стали жертвой манипуляций и политических технологий” (Протесты-2020, 2020). Например, в одном из сюжетов утверждается, что западные, в частности американские сценарии, направлены, прежде всего, на радикализацию протеста, создание образа сакральных жертв и т.д. Реализуется данная стратегия согласно труду (так называемой “методички”) , озаглавленной “От диктатуры к демократии” авторства 
американского политолога Джина Шарпа, с помощью которой осуществлялись революции и государственные перевороты во многих странах мира, в том числе и Беларуси (Протесты в Беларуси..., 2020) Кроме того, “протесты выгодны как и для ЕС, который подстрекает радикализацию протестов в Беларуси” (Навигатор повел не туда..., 2020), так и для США, “которым принадлежит ключевая роль в организации немирных форм протеста" (Радикализация, экстремизм и терроризм..., 2020).

Как следует из сюжетов телеканала ОНТ, в дестабилизации ситуации заинтересованы, в первую очередь, глобальные политические игроки, тогда как такие государства как Польша Литва и Чехия являются странами сателлитами в деле организации государственного переворота в Беларуси. Учитывая это, особенно недружественной и резкой является риторика относительно соседних Польши и Литвы, которые “будучи несамостоятельными странами, живущими за счет дотаций являются “цепными собаками”, “гиенами Запада” в отношении Беларуси” (Радикализация, экстремизм и терроризм..., 2020). Кроме того, именно Варшава и Вильнюс называются одними из основных городов, в которых действовали центры координации акций протестов 2020 года в Беларуси (Протесть-2020, 2020).

Исходя из вышеупомянутого, белорусская и российская оппозиция и ее лидеры трактуются как марионетки в руках Запада, используемые для борьбы против Беларуси и России (Санкиии и давление на Россию, 2020). При этом, именно “Польше, которая в течение около десяти лет создавала протестную медийную и гуманитарную инфраструктуру и эксплуататорские настроена в отношении Беларуси, принадлежит одна из главных ролей в этом процессе”. В свою очередь, Литва называется “империалистическим государством, пытающимся угнетать белорусов во имя западных ценностей и демократии”.(Политолог Алексей Дзермант о ситуации в Беларуси..., 2020). В качестве инструментов влияния этих стран и одними из основных очагов формирования прозападно настроенного молодого поколения называются Европейский гуманитарный университет (ЕГУ) в Литве и Стипендиальная программа Правительства Республики Польша имени Кастуся Калиновского. В этом же контексте в одном из сюжетов телеканала 
ОНТ приводятся слова Александра Лукашенко о том, что “победа революции в Беларуси - это национальный интерес Польши” (Проmecmbl-2020, 2020). При этом проводится черта разграничения между гражданами этих стран (Польши или Литвы) и их политическими элитами, которые не отстаивают интересов своих обществ.

Одновременно с уличением Запада в агрессивной политике относительно Беларуси, переносится внимание на внутриполитические проблемы. Утверждается, что в частности “в США, не существует свободы слова и не защищаются права человека” (Наши новости ОНТ: “Свобода” слова в США, 2021). В одном из сюжетов, посвященных теме кризиса в Польше Литве и Украине, говорится о том, как эти страны, которые ведут недружественную политику по отношению к Беларуси, переживают острый кризис, связанный с массовыми протестами и оттоком человеческого капитала, а их политики потеряли доверие народа Попутно транслируется мысль, что протесты на Западе (в частности в Польше 2020 года) имеют четко выраженный социально-экономический подтекст (Протесты в мире..., 2020). В то же время протестные движения на постсоветском пространстве, в частности в Беларуси, не связаны с каким либо общественным недовольством, а являются исключительно следствием западных политических технологий, манипуляций общественным сознанием и провокациями центров информационно-психологического воздействия. Паралельно с этим ударение ставится на внутренние проблемы, существующие на Западе.

Характерным примером является наличие материалов о проявлениях нацизма в отдельных европейских странах, в которых пытаются героизировать данную идеологию (Жесткие законы и резолющия ООН..., 2020). Одновременно с этим освещаются инициативы, противодействующие возрождению идей и проявлений нацизма внутри Беларуси, с которым, в частности, ассоциируется бело-красно-белый флаг - символ белорусского протеста (Флаги и символы коллаборационистов..., 2020). Обращается особое внимание на двойные стандарты, которыми руководствуется Запад по отношению к Беларуси, поскольку “применение силы, направленное на подавление протестов в западных странах (Германии, Польши или Франции) еще более жестоко чем в случае Беларуси" (Выборы в Беларуси-2020, 2020). 


\section{Итоги}

С началом политического кризиса и усиления российского информационного влияния в Беларуси на государственном телевидении наблюдается усиление антизападной риторики с одновременным продвижением пророссийских нарративов. В то же время, принимая во внимание данные социологических исследований касательно отношения белорусского общества к Западу, можно констатировать, что на данном этапе белорусы не склонны разделять резкую антизападную риторику, транслируемую пророссийскими медиа, при одновременном желании сохранения конструктивных связей с Россией.

На основании осуществленного анализа контента телеканала ОНТ можно утверждать, что страны Запада упоминаются в основном в контексте деструктивного влияния на внутриполитическую ситуацию в Беларуси. Запад в целом изображается как агрессивное объединение государств, пытающееся посредством так называемых “цветных революций” атаковать Беларусь и Россию. Отдельные страны, например, Польша и Литва позиционируются как недружественные Беларуси соседи, которые, имея к ней территориальные претензии, являются несамостоятельными марионетками и вассалами США. В отдельных сюжетах акцентируется внимание на внутренних противоречиях и проблемах западных государств, что свидетельствует об их деградации и несостоятельности. Таким образом, зрителю фактически навязывается биполярная картина мира, предлагающая белорусам выбор между враждебным агрессивным Западом и дружественной и стабильной Россией.

Стоит также отметить, что нарративы, транслируемые на телевидении, в целом совпадают с теми, которые продвигаются на пророссийских интернет ресурсах (Елисеев, 2020). Однако, по резкости и агрессивности высказываний контент, представленный на телеканале ОНТ, является несколько более сдержанным по сравнению с пророссийскими пропагандистскими интернет-сайтами. Тем не менее, наличие широкой сети прокремлевских интернет-медиа и соответствующей ориентации белорусских телеканалов (в частности ОНТ), которые синхронизируют свою информационную повестку, в совокупности создает единый пропагандистский фронт для массового воздействия на белорусскую аудиторию. 


\section{DR TARAS POLOVYI}

Department of International Information

Lviv Polytechnic National University

Stepana Bandery St. 14, Lviv (Ukraine)

taraspolo@gmail.com

\section{Литература}

Александров, А., Бастунец, А. (2020). Медиа в Беларуси. Рьнок, законь и инбормационная безопасность. Аналитический доклад. Источник:

https://baj.by/sites/default/files/event/files/2020/report_media2020_rus.pdf.

Федоров, А. (2020). Антизападничество Минска: имманентное или конъюнктурное? В: В тумане гибридной войны: Природа российского влияния в Беларуси. Источник: https://bsblog.info/wp-content/uploads/2020/12/Booklet-2020.pdf.

Гибридная интервениия. Лукашенко передаёт контроль над Беларусью Кремлю (2020). Источник: https://isans.org/articles/gibridnaya-intervencziya.html.

Елисеев, А. (2019). Кардинальные перемень в антибелорусской дезинформации и пропаганде: анализ количественных и качественных изменений. Исследовательский центр EAST (Eurasian States in Transition). Апрель 2019. Источник: https://east-center.org/wp-content/uploads/2019/04/Belarus-DisinformationPropaganda-2019-RU.pdf.

Елисеев, А. (2020). Прокремлевская пропаганда в Беларуси: Классификация нарративов. https://isans.org/wp-content/uploads/2020/11/propaganda-in-belarusreview.pdf.

Елисеев, А. (2020). С информационным суверенитетом Беларуси покончено за три недели Источник: https://isans.org/columns/s-informaczionnym-suverenitetombelarusi-pokoncheno-za-tri-nedeli.html.

Лукашенко подтвердил работу российских пропагандистов на ТВ в Беларуси (2020). Источник: https://www.ukrinform.ru/rubric-world/3085466-lukasenkopodtverdil-rabotu-rossijskih-propagandistov-na-tv-v-belarusi.html.

Marszałek-Kawa, J., Plecka, D., Hołub, A. (red.). (2018). Social Security. Selected Aspects. Toruń: Wydawnictwo Adam Marszałek.

Мониторинг пророссийской пропаганды в медиа Беларуси (2019). Источник: https:// baj.by/sites/default/files/analytics/files/monitoring-prorossiyskoy-propagandy-vmedia-belarusi.pdf

Морозов, А. (2020). Михаил Дорошевич: Беларусская медиасистема польностью разрушена Источник: https://isans.org/articles/mihail-doroshevich-belarusskayamediasistema-polnostyu-razrushena.html?fbclid=IwAR2Xhr8j92J50McsKM9MOy 9fx0GP4LS81KIKpvqOm89wwgL4-RbSjK6PjPY.

Республика Беларусь в зеркале сочиологии: сборник материалов соииологических исследований (2018). Минск: Информационно-аналитический центр при Администрации Президента Республики Беларусь. Источник: http://eschool.by/ wp-content/uploads/2019/04/011.pdf. 
Рудкоусскі, П. (2020). Слабая национальная идентичность - почва для антизападных настроений Источник: https://belinstitute.com/be/article/slabayanacionalnaya-identichnost-pochva-dlya-antizapadnykh-nastroeniy.

Toal, G., O’Loughlin J., Bakke K.M. (2020). What's driving the Belarus protests? Источник: https://www.washingtonpost.com/politics/2020/08/21/whats-driving -belarus-protests.

Białorusini o Polsce, Rosji i sobie (2021). Источник: https://www.osw.waw.pl/pl/ publikacje/komentarze-osw/2021-01-29/bialorusini-o-polsce-rosji-i-sobie.

Санкиии и давление на Россию: как создается "управляемый хаос» и кому это нужно? (2020). Источник: https://www.youtube.com/watch?v=rJuT8tuu PiY\&ab_channel=ТелеканалОНТ.

Лукашенко: Я не единожды говорил, что Беларусь им нужна как трамплин для атаки на Россию (2020). Источник: https://www.youtube.com/watch?v= GDpuxCE8wts\&ab_channel=ТелеканалOHT.

Лукашенко российским СМИ: Если сегодня Беларусь рухнет, следующей будет Россия (2020). Источник: https://www.youtube.com/watch?v=GDpux CE8wts\&ab_channel=ТелеканалОНТ.

Чем грозит выход ситуации из-под контроля? Мнение экспертов о ситуации в Беларуси (2020). Источник: https://ont.by/news/chem-grozit-vyhod-situaciiiz-pod-kontrolya-mnenie-ekspertov-o-situacii-v-belarusi.

Протесты-2020. Причинь уличных бурлений в мире и почему револючия в Беларуси сорвалась? (2020) Источник: https://www.youtube.com/watch?v= PnNWLvjVXS0\&ab_channel=ТелеканалOHT.

Флаги и символь коллаборационистов: как не допустить возрождения идей нацизма (2020). Источник: https://www.youtube.com/watch?v=94rtWyx J8aE\&ab_channel=ТелеканалОНТ.

Зюганов о ситуации в Беларуси и украинском Майдане, расколе оппозиции, Лукашенко и Путине (2020). Источник: https://www.youtube.com/ watch?v=VwuRJ5zla8M\&ab_channel=ТелеканалOHT.

Эксперты: Беларусь столкнулась с небывальм внешним давлением и вмешательством во внутренние дела (2020). Источник: https://ont.by/news/ekspertybelarus-stolknulas-s-nebyvalym-vneshnim-davleniem-i-vmeshatelstvom-vovnutrennie-dela.

Кто и зачем призывает белорусов подорвать собственную экономику? Репортаж ОНТ (2020). Источник: https://www.youtube.com/watch?v=Ux2avy UmXJ4\&ab_channel=ТелеканалОНТ.

Протесты в Беларуси. 7 мгновений иветной революиии, которая не удалась (2020). Источник: https://www.youtube.com/watch?v=yCh-SFL9zwM\&ab_channel= ТелеканалОНТ.

Навигатор повел не туда: хронологии и результаты акиий протеста в Беларуси (2020). Источник: https://www.youtube.com/watch?v=0V6Gpr09 wa4\&ab_channel=ТелеканалОНТ.

Политолог Алексей Дзермант о ситуации в Беларуси, попытках захвата власти и помощи России (2020). Источник: https://www.youtube.com/watch?v= -ldQfxH-7rA\&ab_channel=ТелеканалОНТ. 
Наши новости ОНТ: “Свобода” слова в США (2021). Источник: https://www.youtube. com/watch?v=bxybGPnL6bk\&ab_channel=ТелеканалOHT.

Протесть в мире: почему политики в Польше, Литве и Украине потеряти доверие народа? (2020) Источник: https://www.youtube.com/watch?v= WAvUdybmi7E\&ab_channel=ТелеканалОНТ.

Жесткие законы и резолюиия ООН. Как Европа борется с героизацией нац,изма? (2020) Источник: https://www.youtube.com/watch?v=lYYPbhcVtjQ \&ab_channel=ТелеканалОНТ.

Выборы в Беларуси-2020: до и после 9 августа. Горячие политические игры и грязные политтехнологии (2020). Источник: https://www.youtube.com/watch?v =JrvCo0ZJXys\&ab_channel=ТелеканалОНТ. 